\title{
An Approach to Hotel Services Dynamic Pricing Based on the Delphi Method and Fuzzy Cognitive Maps
}

\author{
Dimitris K. Kardaras, ${ }^{1, *}$, Xenia J. Mamakou ${ }^{1}$, Bill Karakostas ${ }^{2}$, \\ and George Gkourakoukis ${ }^{1}$ \\ ${ }^{1}$ Business Informatics Laboratory, Dept. of Business Administration, \\ Athens University of Economics and Business, 76 Patission Street, Athens 10434, Greece \\ \{kardaras, xenia\}@aueb.gr, GeorgeGk@outlook.com \\ ${ }^{2}$ Centre for HCI Design, School of Informatics, City University, Northampton Sq., \\ London EC1V 0HB, UK \\ billk@soi.city.ac.uk
}

\begin{abstract}
E-tourism services open up new opportunities for businesses to expand and when possible to gain completive advantage. Dynamic pricing is an area of interest for both researchers and professionals. It's the process of price specification in a way that best suits a tourism organization under certain circumstances that reflect its competitive environment. Many research studies have addressed dynamic pricing from different perspectives. This study suggests that the use of a hybrid approach that combines Delphi method and fuzzy cognitive maps is suitable for it introduces fuzzy logic in order to capture the subjectivity and vagueness involved into evaluating the business settings, but it also provides for the necessary flexibility in analyzing the assumptions and the implications of different pricing scenarios.
\end{abstract}

Keywords: dynamic pricing, Delphi method, fuzzy cognitive maps, hotel management, e-tourism.

\section{$1 \quad$ Introduction}

Tourist arrivals around the world will increase over $200 \%$ by 2020 as predicted by the World Tourism Organization [35]. The hotel service has four characteristics [15], [36]: Intangibility: referring to the nature of the service. A service consumer cannot judge the quality of a service until the service is consumed. Inseparability: which implies that both the customer and the service provider should be present so that the service takes place. Variability: implying that the service depends on the provider, the time and the location that is consumed by the customer. Perishability: which refers to the inability of the services to be stored and consumed another time. Heterogeneity: implying that when in contrast to the products, services can be differentiated, especially due to the fact that they are intangible.

Tourism is a highly competitive business but its competitive advantage is no longer natural, but increasingly driven by science, information technology and innovation [5]. The Internet represents already the primary source for tourist to gather 
information for travelers, since $95 \%$ of Web users use the Internet to gather travel related information and about $93 \%$ indicate that they visited tourism Web sites when planning for vacations let alone the fact that the number of people who search the Internet for tourism related information increases rapidly [5]. Travelers increasingly resort to the Internet to search for tourism offers, to collect destination information and to organize their trips. The available information is there on the web and steadily increasing as well, thus making competition among business more intensive. In such a volatile environment, with well-informed competitors as well as customers, hotel management should adapt their pricing policy in order to meet the requirements of tourists but also to respond to challenges of the competition.

However, one of the most important features in hotel management, also in the tourism industry as a whole, is that many of its products / services are perishable. This makes it more difficult to set the appropriate price for a given business environment at a given point in time [10]. In addition, bearing in mind that tourism is extremely vulnerable to various external pressures and events, such as natural disasters and terrorist attacks, one cannot be sure for its demand. Therefore, dynamic pricing becomes an even more complicated decision problem [34]. As a result, drawing the appropriate pricing policy that can flexibly adjust to current circumstances is of paramount importance for hotel management.

\section{Literature Review}

One of the many implications that e-tourism has brought to tourism industry is the way that tourism businesses set the price for their services. Dynamic pricing, stems from dynamic packaging, which can be defined as "the combining of different travel components, bundled and priced in real time, in response to the request of the consumer or booking agent" [5]. The problem in the dynamic pricing in the case of the hotel industry is related to the unknown demand distribution of this service [34]. Lewis and Chambers (1989), in Danziger et al., (2004) [10], claim that "pricing in the hotel industry appears to be unscientific, self-defeating, myopic, and not customerbased". Other than the seasonality, hotel service prices are influenced by factors such as unknown demand distribution, income availability, the political stability in a tourism destination, the terrorist attacks, etc. [34].

Dynamic pricing originally introduced in the early 2000s from hotel chains, such as Hilton, InterContinental and Ledra Marriott [23]. Dynamic pricing, which is also known as yield management pricing policy [2], [30] is commonly used in the hotel industry, implying "a method that can help a firm to sell the right inventory unit to the right customers at the right time and at the right price, and thus to help a company optimize its profit". It is also defined as a sophisticated way of managing the offer/demand by manipulating prices and available capacity simultaneously [30]. Dynamic pricing is related to policies such as the Last Room Availability (LRA) and the Best Available Rate (BAR). The LRA policy offers better prices for certain number or types of rooms. A hotel could for example adopt the LRA policy for all room types, 365 days a year, as opposed to a static agreement, where LRA is offered in only 2 
room types [29]. On the other hand, BAR ensures customers that the price they pay is the best rate a hotel can offer, given the demand for that particular day [29].

There are two ways for consumers and service providers to reach a dynamic pricing agreement. The first is associated to a client who has a significant volume for a specific hotel. The amount of discount off of the Best Available Rate (BAR) reflects on the one hand the volume that the client brings to this hotel and on the other the travel patterns of the client [29]. The second way to reach a dynamic pricing agreement is associated to the multi-location and the minimal volume of this agreement, in which case, the client offers small volumes for several locations; thus the hotel chain will offer a minimal discount off of the Best Available Rate (BAR) [29]. A blend of these two ways is also possible. Given the fact that the pricing in the case of the hotel industry is based on a constrained supply and a fluctuating demand, the static model of pricing is not realistic. Hence, the dynamic pricing model is regarded as a reasonable solution [29]. Several methods have been applied for hotel services pricing such as the Activity Based Costing - ABC [9], the thumb approach and the Hubbart formula. According to the first, "the room price is equal to $1 / 1000$ of the investment price", whereas according to the Hubbart formula "the room rate equals the satisfied room revenue divided by the anticipated rooms sold, and satisfied room revenue is the cost of the hotel and the owner-desired profit"[6]. Recent studies indicate the value of dynamic pricing in terms the financial but also other tangible or intangible benefits it produces for hotels.

\section{Methodology}

The aim of this research is to determine the factors that mostly affect the process of dynamic pricing and to develop a model that supports the process of dynamic pricing. This study consists of two phases. The first phase adopts the Delphi method and captures the opinions of a group of 30 experts, with respect to the most influential pricing factors. A two-round Delphi method identified 20 pricing variables which were then included in the dynamic pricing model. In the second phase the same group of experts had to indicate the interrelationships among the factors identified during the first phase. Then, this study utilizes fuzzy cognitive maps in order to model the interrelationships among the factors identified and to provide a model that supports pricing scenarios analysis. The experts were asked to express their beliefs with respect to the strength and polarity of all possible causal relationships among the pricing factors identified from the Delphi method.

\subsection{Delphi Method}

The Delphi method (DM) was originally developed by Dalkey and Helmer [8]. It can be used to acquire experts' knowledge and beliefs and reach a reliable consensus among the experts [24]. DM rounds (up to four) of experts' questioning provide the experts with important information, like medians, averages and deviation from the previous rounds, so that they can rethink and revise their original beliefs and 
assumptions. Studies show that the experts' opinions converge towards the average of the group's opinions [4]. DM is applied through a series of recurring questions, usually in the form of questionnaires to a group of experts. After each round of questioning, the questions of each subsequent cycle to each member are accompanied by information on the responses of the other group members, which are presented anonymously. In this way, feedback is given for the experts to revise their opinions. According to Skulmoski et al. [32], the Delphi method is characterised by the Anonymity of the Delphi participants, the Iteration, through which the participants reconsider their opinions, the Controlled feedback, since it provides feedback information to the experts regarding the other members' opinions from previous rounds and Statistical aggregation of the experts' responses, thus producing the consensus of the group. $\mathrm{DM}$ is simple and flexible [32], it avoids a direct confrontation among the participants during the application of the method [28] and it also offers the experts feedback in order to review their assumptions and positions [27].

Many methods have been proposed to combine experts' opinions such as mean, median, max, min, mixed operators [20]. This research uses the geometric mean to represent experts' consensus. Thus, the importance of each of the factors identified is calculated by using the geometric mean of all the corresponding answers of the participants. The geometric mean has been used in the literature as one of the best ways to aggregate experts' opinions [16].

According to Mullen [26], there is no consensus regarding the size of the experts panel required by DM. Panel sizes as little as 9 experts [12] have been used in DM, or groups of 10 experts [3], 13 experts[22], or 31 members[16]. DM studies have also engaged groups as large as low hundreds, or even thousands in some studies in Japan [21]. The panel size of 30 experts in the current study is therefore, within the recommend range.

\subsection{Fuzzy Cognitive Maps}

A Fuzzy Cognitive Map (FCM) is a graph that consists of a number of nodes $\mathrm{Ci}$ representing the concepts of the domain in study. These nodes are connected to each other with weighted arcs $\mathrm{W}(\mathrm{i}, \mathrm{j})$ showing how concept $\mathrm{i}$ is causally affected by concept $\mathrm{j}$. The arcs that connect two concepts have weights that correspond to fuzzy qualifiers, such as 'a little', 'moderately', 'a lot'. Furthermore fuzzy numbers can be assigned in order to show the extent to which a concept affects another. FCMs are commonly used to model and study perceptions about a domain, to investigate the interrelationships among its concepts and to draw conclusions based on the implications of specific scenarios. The impact among the concepts of a FCM is estimated using the indirect effect. In other words, the impact caused due to the interrelationships among the concepts along the path from a cause variable (X) to an effect variable (Y) and the total effect, i.e. the sum of all the indirect effects from the cause variable $X$ to the effect variable Y [14].

FCMs are represented by means of an $\mathrm{NxN}$ matrix, where $\mathrm{N}$ is the number of the concepts in the FCM with $i$ and $j$ representing concepts in the FCM. Every value of this matrix represents the strength and direction of causality between interrelated 
concepts. The value of causality is assigned values from the interval $[-1,+1]$. According to [31]:

- $>0$ indicates a causal increase or positive causality from node $\mathrm{i}$ to $\mathrm{j}$.

- $=0$ there is no causality from node $\mathrm{i}$ to $\mathrm{j}$.

- $<0$ indicates a causal decrease or negative causality from node $\mathrm{i}$ to $\mathrm{j}$.

The multiplication between matrices representing FCMs produces the indirect and total effects [37] and allows the study of the impact that a given causal effect D1 is causing. Causal effects can be represented with a $1 \mathrm{xN}$ vector [1]. This impact is calculated through repeated multiplications: ExD1 $=\mathrm{D} 2, \mathrm{ExD} 2=\mathrm{D} 3$ and so forth, that is, $\mathrm{ExDi}=\mathrm{Di}+1$, until equilibrium is reached, which is the final result of the effect D1. Equilibrium is reached when the final result equals to zero, i.e. all cells of the resulting vector are equal to zero (0) and there is no any further causal impact caused by any concept. Different thresholds, depending on the modelling needs, restrict the values that result from each multiplication within the range $[-1,+1]$. Therefore, if a value is greater than $(+1)$ then it is set to $(+1)$, or it is set to $(-1)$ if the resulting value exceeds the lower limit of $(-1)$. For example, a threshold of $(+/-0.5)$ implies that if the resulting value is greater than $(+0.5)$ or lower than $(-0.5)$ then the value is set to $(+1)$ or (-1) respectively. FCMs have been used in many applications such as in modelling complex dynamic, which are characterized by strong non linearity [33], in personalised recommendations [17], [25], in managing relations in airline services [13], in systems modelling and decision making [14], in EDI design [18] and in EDI performance evaluation [19].

In order to construct the FCM, this study adopts the approach proposed by [3-4], who propose the development of an FCM for ERP tools selection based on experts' consensus, which was reached after a two-round consultation with the use of the Delphi method. The FCM is constructed by considering the median of the experts' responses in order to represent the magnitude of causality among the FCM concepts. As for the sign of each causal relationship, the sign that the majority of the experts propose is selected.

\section{Delphi Method Results}

The group of experts who agreed to participate in this study had to specify the important factors that influence hotel service prices. The two-round Delphi method resulted in the following list of 20 factors.

The results show that trust is the foremost important factor that influences service price and the decision of a customer to proceed in booking. It is interesting to note that experts find trust even more important than demand. It implies that long term good reputation of the hotel and its highly appreciated services among the customers can provide the foundation for the hotel management to adjust pricing policies even at hard times. Therefore, hotel management should pay special attention to increasing its customers' trust towards their hotel services. 
Table 1. List of factors affecting dynamic pricing

Factors affecting dynamic pricing

Geometric

Mean

Trust: Hotels ability to reflect all the necessary reassurances to gain cus-

4.39 tomers trust.

Product's description: All the necessary information that may interest the customer regarding offered services and hotel facilities.

Awareness and Star Rating: The importance of hotels brand awareness as well as its Star Rating Categorization.

The distribution channel: The distribution channel that the company uses for its dynamic pricing, and its nature. (Internet, mobile devices, agencies etc).

Forecast ability: Hotel's ability to forecast future bookings (short and long term).

Booking incentives: The incentives that hotels offer to its customers in order to increase bookings efficiency. Eg: LRA (Last Room Availability), BRG (Best Rate Guarantee) etc.

The profile of the customer: The nature of the potential customer. For example, there are high-value customers willing to pay more and lowvalue customers looking for last minute offers.

Customer's behavioural trends: The way customers react. For example, buyers tend to request a ceiling or cap rate because they don't like to drive into the unknown.

Competition: The competition between hotels operating in the same market.

Market orientation: How clear is the orientation of the market through which the hotel offers its services? There is a variety of markets and most of them, present their prices as the best existing prices. This can confuse customers.

Heterogeneity among hotels: Usually, many hotels operate in the same area, of the same heterogeneous type of service and ranking.

Demand and availability: Demand and availability over the region where the hotel operates.

Economical and political situation: Economical and political situation on the region where the hotel operates.

Legal constraints: There may exist legal constraints regarding the nature of the offers, such as maximum and minimum possible prices.

Booking Season: A product may have different price on an ordinary date and different on a holiday season.

Customer's perceptions: Customer's perceptions of price and satisfaction. The perception of price fairness over offered services etc.

Customer's preferences: Depending on the product, there might be various

preferences that define the final product price (wifi, breakfast/dinner etc).

Room availability: Room availability in the hotel.

Historical records: Historical records that allow a company to make price decisions based on earlier records.

Customer arrival rate: The arrival rate of new customers at the hotel. 


\section{$5 \quad$ Fuzzy Cognitive Mapping}

Following the Delphi method, the experts were asked to judge the direction and strength of interrelationships among the pricing factors. The median was calculated in order to specify the strength of factors' interralationships, for it allows for positive or negative signs to be modelled in the FCM. As for the sign of each relationship, following the method by Bueno and Salmeron [3], it is defined according to the majority of the experts' answers. By analyzing experts' responses the following part of the complete FCM was constructed:

\begin{tabular}{|c|c|c|c|c|c|c|c|c|}
\hline & Trust & Demand & $\begin{array}{l}\text { Customer } \\
\text { Perception }\end{array}$ & $\begin{array}{l}\text { Booking } \\
\text { Season }\end{array}$ & \begin{tabular}{|l|} 
Product \\
Description
\end{tabular} & Price & $\begin{array}{l}\text { Heterogeneity } \\
\text { of Hotels }\end{array}$ & \begin{tabular}{|l|} 
Customer \\
Preferences
\end{tabular} \\
\hline Trust & 0 & \begin{tabular}{|r|}
0,8 \\
\end{tabular} & \begin{tabular}{|r|}
0,6 \\
\end{tabular} & 0 & 0 & 0,2 & 0 & $\begin{array}{l}0,4 \\
\end{array}$ \\
\hline Demand & 0,6 & 0 & 0,6 & 0 & 0 & 0,2 & 0,2 & 0 \\
\hline $\begin{array}{l}\text { Customer } \\
\text { Perception }\end{array}$ & 0 & 0 & 0 & 0 & 0 & 0 & 0 & 0 \\
\hline \begin{tabular}{|l} 
Booking \\
Season
\end{tabular} & 0 & 0 & 0 & 0 & 0 & 0 & 0 & 0 \\
\hline \begin{tabular}{|l} 
Product \\
Description
\end{tabular} & 0 & 0 & 0,6 & 0 & 0 & 0,4 & 0 & 0 \\
\hline Price & 0 & $-0,4$ & 0,2 & 0,4 & 0,6 & 0 & $-0,2$ & 0,4 \\
\hline $\begin{array}{l}\text { Heterogeneity } \\
\text { of Hotels }\end{array}$ & 0 & 0 & 0 & 0 & 0 & 0,4 & 0 & 0 \\
\hline $\begin{array}{l}\text { Customer } \\
\text { Preferences }\end{array}$ & 0 & 0,4 & 0,6 & 0 & 0 & 0,6 & 0,4 & 0 \\
\hline
\end{tabular}

Fig. 1. Part of the Dynamic Pricing FCM

By implementing the FCM as a matrix, several pricing scenarios can be investigated. For example, assume that a hotel operates in an area of low heterogeneity, which implies that hotel services are similar to each other, thus intensifying the competition and subsequently increasing the pressure for lower prices. Other assumptions regarding the current situation of the hotel in the scenario are a high trust that customers hold for the hotel, and high demand. The linguistic variables used to describe the scenario are expressed in terms of the following scale [7]:

Table 2. Linguistic variables and corresponding mean of fuzzy numbers

\begin{tabular}{ll}
\hline Linguistic Values & The Mean of fuzzy numbers \\
\hline Very High & 1 \\
High & 0.75 \\
Medium & 0.5 \\
Low & 0.25 \\
Very Low & 0 \\
\hline
\end{tabular}


Each scenario, which assumes a causal effect, is represented by the ScenarioVector (SV), which is a vector $(1 \mathrm{xn})$, where $\mathrm{n}$ is the number of variables that constitute the dynamic pricing FCM. Drawing on the theory of FCM, by multiplying the SV and the FCM, the management can examine the implication on prices and then decide what the most favourable pricing policies can be assumed and followed. More than one multiplication may be needed, until the system produces a final value for the "Price" variable, i.e. the price adjustment (PA). The sign of the value of "Price" indicates that the system suggests a price increase or reduction. The value indicates that magnitude of the price adjustment which in fuzzy terms can be a very high or high, etc. increase.

Assume the following scenario represented by the activation vector shown in Fig. 2:

\begin{tabular}{|r|r|l|l|l|l|l|l|}
\hline Trust & Demand & $\begin{array}{l}\text { Customer } \\
\text { Perception }\end{array}$ & $\begin{array}{l}\text { Booking } \\
\text { Season }\end{array}$ & $\begin{array}{l}\text { Product } \\
\text { Description }\end{array}$ & Price & $\begin{array}{l}\text { Heterogeneity } \\
\text { of Hotels }\end{array}$ & $\begin{array}{l}\text { Customer } \\
\text { Preferences }\end{array}$ \\
\hline 0,7 & 0,8 & 0,7 & 0,4 & 0,1 & 0,7 & 0,2 & 0,1 \\
\hline
\end{tabular}

Fig. 2. FCM scenario

Specifying the threshold at 0.3 the results of the FCM simulation are the following:

\begin{tabular}{|l|l|l|l|l|l|l|r|}
\hline Trust & Demand & $\begin{array}{l}\text { Customer } \\
\text { Perception }\end{array}$ & $\begin{array}{l}\text { Booking } \\
\text { Season }\end{array}$ & $\begin{array}{l}\text { Product } \\
\text { Description }\end{array}$ & Price & $\begin{array}{l}\text { Heterogeneity } \\
\text { of Hotels }\end{array}$ & $\begin{array}{l}\text { Customer } \\
\text { Preferences }\end{array}$ \\
\hline 0,073728 & $-0,046592$ & 0,566016 & 0,188928 & 0,283392 & $\mathbf{0 , 3 6 4 8}$ & 0,057088 & 0,196608 \\
\hline
\end{tabular}

Fig. 3. FCM result

The results in Fig. 3 indicate that price could be increased by low while at the same time customers' perception of the hotel will increase by medium.

By taking into consideration the current price that hotel management can specify the new-price for example, with the following multiplication:

New-Price $=($ Old-Price $)+(($ Old-Price $) \times($ Price-Adjustement $))$.

For example, if Old-Price $=100$ euros and Price-Adjustement $=+$ low, then the New-Price $=100+(100 * 0.3)=130$ euros.

\section{Conclusions}

By applying a hybrid approach that combines the Delphi method and fuzzy cognitive mapping this research work investigates the potential of developing FCMs in order to support dynamic pricing for hotel management. The combination of the two methods has been used in other research works [3] but not in dynamic pricing of hotel services. The proposed approach to dynamic pricing can provide hotel management with a useful tool in their decision making tasks. As a future work, this study suggests the full development and evaluation of a useable tool based on FCM for dynamic pricing. 


\section{References}

1. Banini, G.A., Bearman, R.A.: Application of fuzzy cognitive maps to factors affecting slurry rheology. International Journal of Mineral Processing 52, 233-244 (1998)

2. Bayoumi, A.E., Saleh, M., Atiya, A., Aziz, H.A.: Dynamic Pricing for Hotel Revenue Management Using Price Multipliers (2010),

http: / / alumnus. caltech. edu/ amir/hotel-dyn-pricing-final.pdf

3. Bueno, S., Salmeron, J.L.: Fuzzy modeling Enterprise Resource Planning tool selection. Computer Standards \& Interfaces 30(3), 137-147 (2008)

4. Bueno, S., Salmeron, J.L.: Benchmarking main activation functions in fuzzy cognitive maps. Expert Systems with Applications 36(3), 5221-5229 (2009)

5. Cardoso, J.: E-Tourism: Creating Dynamic Packages using Semantic Web Processes (2005), http: / /www.w3 .org/2005/04/FSWS /

Submissions/16/paper.html

6. Chen, L.: The Luxury casino hotel dynamic price strategy practices for the FIT customer segment. UNLV Theses/Dissertations/Professional Papers/Capstones. Paper 437 (2009), http://digitalscholarship.unlv.edu/thesesdissertations

7. Dagdeviren, M., Yuksel, I.: Developing a fuzzy analytic hierarchy process (AHP) model for behaviour-based safety management. Information Sciences 178, 1717-1733 (2008)

8. Dalkey, N.C., Helmer, O.: An experimental application method to the use of experts. Management Science 9(3), 458-467 (1963)

9. Daly, J.L.: Pricing for profitability: Activity-based pricing for competitive advantage. John Wiley \& Sons, New York (2002)

10. Danziger, S., Israeli, A., Bekerman, M.: Investigating Pricing Decisions in the Hospitality Industry Using the Behavioral Process Method. Journal of Hospitality \& Leisure Marketing 11(2-3), 5-17 (2004)

11. Farahmand, M., Chatterjee, A.: The case for dynamic pricing. Hospitality Upgrade, 154-155 (Spring 2008)

12. Hsu, T.H., Yang, T.H.: Application of fuzzy analytic hierarchy process in the selection of advertising media. Journal of Management and Systems 7(1), 19-39 (2000)

13. Kang, I., Lee, S., Choi, J.: Using fuzzy cognitive map for the relationship management in airline service. Expert Systems with Applications 26(4), 545-555 (2004)

14. Kosko, B.: Fuzzy cognitive maps. International Journal on Man-Machine Studies 24(1), 65-75 (1986)

15. Kotler, P., Keller, K.L.: Marketing management. Pearson, New York (2006)

16. Kuo, Y.F., Chen, P.C.: Constructing performance appraisal indicators for mobility of the service industries using fuzzy Delphi method. Expert Systems with Applications 35, 1930-1939 (2008)

17. Lee, K., Kwon, S.: A cognitive map-driven avatar design recommendation DSS and its empirical validity. Decision Support Systems 45(3), 461-472 (2008)

18. Lee, S., Han, I.: Fuzzy cognitive map for the design of EDI controls. Information \& Management 37(1), 37-50 (2000)

19. Lee, S., Kim, B.G., Lee, K.: Fuzzy cognitive map-based approach to evaluate EDI performance: A test of causal model. Expert Systems with Applications 27(2), 287-299 (2004)

20. Lin, H.Y., Hsu, P.Y., Sheen, G.J.: A fuzzy-based decision-making procedure for data warehouse system selection. Expert Systems with Applications 32, 939-953 (2007)

21. Linstone, H.A., Turoff, M.: Introduction to the Delphi method: techniques and applications. In: Linstone, H.A., Turoff, M. (eds.) The Delphi Method: Techniques and Applications. Addison-Wesley Publishing Company, Reading (1975) 
22. Ma, Z., Shao, C., Ma, S., Ye, Z.: Constructing road safety performance indicators using fuzy Delphi metod and Grey Delphi method. Expert Systems with Applications 38, 1509-1514 (2011)

23. Mannix, M.: Dynamic hotel pricing: Signs of a trend? CWT Vision (4), 35-39 (2008)

24. Mereditha, J.R., Amitabh, R., Kwasi, A., Kaplana, B.: Alternative research paradigms in operations. Journal of Operations Management 8(4), 297-326 (1989)

25. Miao, C., Yangb, Q., Fangc, H., Goha, A.: A cognitive approach for agent-based personalized recommendation. Knowledge-Based Systems 20(4), 397-405 (2007)

26. Mullen, P.: Delphi: Myths and Reality. Journal of Health Organisation and Management 17(1), 37-52 (2003)

27. Nasserzadeh, S.M., Reza, M., Hamed, J., Taha, M., Babak, S.: Customer Satisfaction Fuzzy Cognitive Map in Banking Industry. Communications of the IBIMA (2), 151-162 (2008)

28. Okoli, C., Pawlowski, S.: The Delphi method as a research tool: an example, design considerations and applications. Information \& Management 42(1), 15-29 (2004)

29. Palamar, L.A., Edwards, V.: Dynamic pricing: Friend or Foe? Buckhiester Management (2007), http: / / buckhiester.com/wp/assets / Dynamic-Pricing-White-Paper-2007.pdf

30. Rondan-Cataluña, F.J., Ronda-Diaz, I.M.: Segmenting hotel clients by pricing variables and value for money. Current Issues in Tourism, 1-12 (2012)

31. Schneider, M., Shnaider, E., Kandel, A., Chew, G.: Automatic construction of FCMs. Fuzzy Sets and Systems 93(2), 161-172 (1998)

32. Skulmoski, G.J., Hartman, F.T., Krahn, J.: The Delphi Method for Graduate Research. Journal of Information Technology Education 6, 1-21 (2007)

33. Stylios, C.D., Groumpos, P.P.: Fuzzy cognitive maps in modeling supervisory control systems. Journal of Intelligent \& Fuzzy Systems 8(2), 83-98 (2000)

34. Wang, X.: Dynamic Pricing with a Poisson Bandit Model. Sequential Analysis: Design Methods and Applications 26(4), 355-365 (2007)

35. WTO. World Tourism Organization (2005)

36. Young, L.: From products to services. Insight and experience from companies which have embraced the service economy. John Wiley \& Sons, West Sussex (2008)

37. Yu, R., Tzeng, G.-H.: A soft computing method for multi-criteria decision making with dependence and feedback. Applied Mathematics and Computation 180(1), 63-75 (2006) 